\title{
WHAT TO DO UNTIL THE
}

\section{PSYCHIATRIST}

\section{COMES}

STUART M. FINCH, M.D.**

* Presented at February 1963 Meeting of District $V$ of The American Academy of Pediatrics.

** Professor of Psychiatry and Director of Children's Psychiatric Hospital, University of Michigan Medical School.

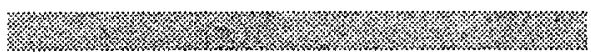

\section{$T$}

HE American pediatrician today, while entirely capable of taking care of the majority of his child patients himself, has available consultants to whom he can refer those special cases for which additional refined technics are necessary. For example, he will offer excellent care to a child with rheumatic fever, but if subsequent valvular damage calls for the services of a cardiac surgeon, appropriate arrangements will be made. Similarly, when an ordinary case of measles or mumps becomes complicated by central nervous system damage, the pediatric neurologist stands ready to be of assistance. However, not a small part of the pediatrician's practice is comprised of youngsters who have emotional or mental disorders. Some of these he can handle, but many others would seem to require the services of a child psychiatrist. Here the pediatrician meets a difficult obstacle. Child psychiatrists do not exist in sufficient numbers to meet the demand of the pediatricians for such specialized services. In essence, the child psychiatrist "is not coming." 
Here are a few statistics. There are only about 300 Board Certified Child Psychiatrists in the United States today. This Board, established in 1959, is relatively new. While certifications are being made in increasing numbers, the total number of recognizably disturbed children is rising even more rapidly. A recent poll of the 12,000 members of the American Psychiatric Association revealed that only about 2,500 were willing to see or work with children. Thus we are dealing with perhaps 300 Certified Child Psychiatrists and a total of 2,500 psychiatrists who deal with youngsters. Various estimates have indicated that from 7 to 12 per cent of the grade school children in the United States are sufficiently emotionally disturbed to need treatment. This represents a total of $21 / 2$ to $41 / 2$ million youngsters. It should also be borne in mind that psychiatric treatment is ordinarily much more time consuming than most other medical treatments. A youngster and his family may have to be seen once, twice or more times per week over many months. If we take these several million children and spread them among the existing psychiatrists, it is obvious that literally, "the psychiatrist is not coming" -and someone has to act for him.

Interest in mental health is growing in national governmental circles as well as in the local communities. This growth of interest is well illustrated by "Action for Mental Health," the publication of the Joint Commission on Mental Health and Illness, ${ }^{1}$ authorized by Congress to study the present mental health problems of the country and to project some of the needs of the future. In addition there are the recent President's Message to Congress on Mental Health ${ }^{2}$ and the Report of the President's Commission on Mental Retardation. ${ }^{3}$ Each of these reports stresses the magnitude of the problems involved and points out the necessity for the participation of the total medical profession as well as all other mental health disciplines. In the case of mental health in children, the reference in these reports to the necessity for the involvement of the total medical profession certainly includes the pediatrician.

\section{WHERE IS PEDIATRICS NOW?}

The "New Pediatrics" stresses the role of prevention. The new pediatrician of today, while well versed in many areas of preventive medicine and highly proficient in his technics, is often unskilled in mental health and the handling of emotional problems. It is probably fair to say also that the majority of pediatricians who currently are completing their residency training are receiving relatively scant knowledge of the diagnosis and management of emotional and mental disorders in children. The relatively short twoyear residency program presents an enormous amount of material to be learned and a great number of patients who must be seen. This extremely busy schedule makes it quite diffcult to include a sufficient exposure to emotional and mental disorders in youngsters and their families to make it a meaningful experience in this direction, and there may be little glamor or excitement attached to the whole concept of mental health. The scarcity of child psychiatrists who are in a position to do the proper teaching in such residency programs is part of the problem. To this scarcity is added the administrative difficulty arising because roost child psychiatrists in a training center are usually attached to the Department of Psychiatry. This serves to emphasize the distance between the pediatrician and the child psychiatrists and makes adequate liaison an added burden.

With this minimal exposure to psychiatric problems in children during a pediatric residency, it is no wonder that child psychiatrists and pediatricians do not communicate well with each other. The pediatrician may accuse the child psychiatrist of not really being a "doctor," whereas the child psychiatrist often assumes that the pediatrician does not "really understand" the personalities of the patient or his family. However, this situation is not always true, and it is not at all uncommon to find pediatricians who have been in practice for a time asking for additional courses in psychiatry. 
WHY DOES THE PEDIATRICIAN FIND PSYCHIATRY DIFFICULT?

The pediatrician often finds many reasons why he does not feel comfortable with the principles of child psychiatry. While it is true that such principles may have been taught to him in esoteric psychiatric jargon, other more basic reasons prevent him from becoming comfortable in this area. First of all, psychiatric principles deal primarily with emotions and ideas. These are relatively intangible concepts and are far removed from the very concrete, measurable things such as blood counts, gastric analyses, blood sugar measurements and the like. Not only that, but the bulk of child psychiatric work is done without the usual "props" to which the pediatrician has become accustomed. The stethoscope, otoscope, tape measure, scale and other such instruments are an integral part of pediatric practice and without them the physician may feel at a loss. Furthermore, in dealing with emotionally disturbed children and their parents the concept of the unconscious must be taken into account. The unconscious is that large portion of the psyche which functions in ways that are thoroughly alien to our conscious mental processes. Time does not exist in the unconscious. Opposites, such as love and hate, can co-exist simultaneously. Outside events do not change matters in the unconscious, and logic does not prevail. As an example, dreams which often are shrugged off as being silly and meaningless do stem from unconscious mental processes and if properly unraveled do have meaning.

Another problem which faces the pediatrician in dealing with emotional problems is the psychological resistance in the patient or the parents. In his usual day-to-day work the pediatrician expects parents to follow his instructions. They are to give the child the medication he prescribes, bring him in for the tonsillectomy which has been recommended, or make return visits at specified intervals. When the pediatrician begins to delve into emotional matters, however, he is often met by unconscious resistances which prevent parents or child from carrying out his recommendations. He tells the overprotective mother to be less overprotective and she fails in her attempts. He points out to the quarreling parents that their arguments are detrimental to the child, but the quarrels continue. Such psychic resistances can be frustrating and, if not well understood, lead to failure in management.

A final problem which confronts the pediatrician in dealing with emotional difficulties is transference. This is the distorted emotional attitude brought by the patient and invested upon the physician. Such transference can be positive in the form of great admiration, or negative in the form of hostility. While such reactions are unrealistic, they can easily stir the pediatrician into countertransference which is an equally distorted, unrealistic response to the patient's attirude. This combination of affairs leads to thorough confusion and more often than not to a lack of improvement on the part of the patient.

\section{WHAT KINDS OF CHILDREN ARE YOU CONCERNED WITH?}

While it is impossible to accurately simplify emotional and mental disorders in children, an attempt in this direction seems justified. It should be borne in mind that this approach is only schematic and cannot be adhered to rigidly.

Perhaps the simplest of all are those early problems which stem from a faulty parental approach. Parents may adopt attitudes and methods through ignorance rather than through difficulties in their own personalities. They may be too strict or too lenient. A father may not recognize the importance of his role in the family. Such difficulties are remedial with relatively simple advice if the relationship with the pediatrician is a good one.

The group of youngsters with emotional difficulties stemming primarily from the existence of physical disabilities should be mentioned. These are children who either suffer from congenital defects or have developed physical disabilities early in childhood. Such problems have led parents to distort their own attitudes, usually toward rejection or 
overprotection. The result is a disturbance in the maturation of the child. Here again the wise pediatrician can assist parents in understanding some of the reasons for their distorted attitudes, and help them adopt more healthy attitudes toward the youngster.

Another group of youngsters are those whose difficulties stem primarily from central nervous system damage. While such children may suffer any degree or type of brain damage, we are concerned here primarily with those whose organic involvement has produced some type of behavioral disorder. Most frequently they are youngsters with a short attention span, hyperactivity, impulsivity, distractibility, restlessness, emotional instability and difficulty in learning by experience. Here the physician has a task of communicating to parents, in an understandable fashion, some of the problems associated with brain damage. He also has the responsibility of helping them plan an adequate program for the child. The child's aberrant reactions often tend to bring forth retaliation from parents, school and community and only intensify the whole problem.

There are also those who suffer primarily from anxiety or other neurotic difficulties. In general, these are inhibited youngsters who have basic immaturities within themselves, but who strive to keep these immaturities out of consciousness. Typical examples are the chronically anxious youngster; the overly good, perfectionistic, obsessional child; and the fearful, phobic child. They have large consciences which forbid awareness of inner immaturities. They attempt through a variety of means to contain this perpetuated immaturity and thus develop various neurotic characteristics. The chronically anxious child may resemble the youngster with mild brain damage in that he is hyperactive, has a short attention span, and at times seems impulsive. $\mathrm{He}$ is, however, much more guilty and concerned about his own behavior than is the youngster with brain damage.

The next large group are those with chronic character disorders. They manifest their diffculties in the form of distorted behavior patterns. Typical is the passive-aggressive child who says yes to whatever is asked of him, but then procrastinates and does not get it done, or the chronic aggressive child who openly rebels. Still another is the passive, effeminant boy who seems to prefer renouncing his masculinity. These, like the neurotic children, are basically immature, but they differ because they act out their immaturities. They often do not feel particularly guilty about their aberrant reactions and tend to feel that the problem lies outside themselves.

Another group of youngsters, not as numerous as some of those above, but nevertheless important, are those suffering from psychosomatic illnesses. These disorders, which stem in part from the presence of chronic emotional tension, include such syndromes as ulcerative colitis, bronchial asthma, neurodermatitis and obesity. Such youngsters probably are born with a predisposition toward malfunction in one or another physiological system, and the subsequent development of certain types of emotional difficulties leads to the onset of the physical disorder. The fact that the child is ill both somatically and physi. cally complicates the treatment process. Therapy must often be provided by two or more physicians, and this opens the possibility for physician disagreement and subsequent mismanagement.

The final group of youngsters to be mentioned are those suffering from psychotic disorders. These are not numerous, but they are the most seriously disturbed. They have lost contact with reality and have suffered serious ego breakdown. Early Infantile Autism and the Symbiotic Psychosis of Childhood are primary examples of these cases. Their management is quite difficult and may eventually require institutionalization. Perhaps the greatest contribution to be made in this area by the pediatrician is that of early recognition and the instituting of measures designed to reverse the psychotic disintegration.

\section{WHAT FORMS OF TREATMENT ARE AVAILABLE TO YOU?}

The pediatrician who encounters a youngster suffering from emotional difficulties has several methods of approach available to him. 
He may, of course, refer the youngster and the family to a psychiatrist, but as stressed earlier, a psychiatrist may not be available. If we assume that the pediatrician himself must accept responsibility for dealing with the difficulty, the following treatment modalities are possible choices.

The first, and simplest, is that of parental counseling on a relatively superficial level. This involves re-education of parents along with attempts to favorably influence parental attitudes. Such parental counseling does not have as its primary aim any basic change in inner parental psychopathology. It utilizes the emotional importance with which the average set of parents have invested the pediatrician. It presumes that they can and will listen to the advice and supportive counsel which he has to offer. In parents who are not seriously disturbed such advice and counsel will usually have a beneficial effect. This approach may not completely eradicate the problem, but it may alleviate it considerably. Such an approach may be used with any disturbed child situation, but obviously will work best where parents are most mature. The more serious the parental emotional difficulty, the less they are apt to respond favorably and permanently to such superficial advice and counsel. It can safely be said that in the vast majority of cases, a genuine understanding interest on the part of the pediatrician and the willingness to give reasonable and intuitive advice will be of benefit. Far too many pediatricians feel that the existence of an emotional problem in a family and a child indicates a situation in which they cannot be of help. Most of the advice and counsel about emotional problems currently being given in the United States is by ministers and priests. The pediatrician has often had far more training in the treatment of emotional disorders than has the theologian and should not feel hesitant to give help.

The next mode of treatment is manipulation of the environment. This involves both recognition by the physician of some of the environmental factors which are contributing to the emotional difficulty, and recommendations regarding improvement of such factors.
A child may have been placed in the wrong grade in school, or perhaps even in the wrong school. A home may be kept in constant turmoil by the presence of a senile grandparent. A host of such environmental factors can be responsible for the increase in emotional problems of a child. If these can be recognized by the intuitive physician, recommendations for changes can be made. Such recommendations must take into account realistic problems of the family and must include advice which is feasible.

A third treatment approach involves the use of psychoactive drugs, including both psychic stimulators and tranquilizers. This avenue of treatment is unfortunately often chosen by pediatricians, mainly because it seems to be the easiest and the quickest. It involves the use of one of the "props," namely, the prescription pad. It is true that certain youngsters with brain damage respond favorably to the amphetamines and that other youngsters with emotional and mental difficulties may respond to tranquilizers. Such an approach, however, does not carry with it any real solution of the difficulty. In the case of brain damaged children the use of amphetamines, where they prove successful, is quite proper. The use of tranquilizers, however, in the neurotically anxious child does not really solve any long range problems. The child will not grow out of his neurotic prob. lems, hence permanent use of tranquilizers is obviously unwise. Many teachers today complain that a small segment of children in their classes is over-tranquilized. While these youngsters may be quieter and more manageable than previously, the "treatment" is giving rise to more problems than it is solving. They do not learn well and they are not maturing emotionally.

The pediatrician has available to him another avenue of therapy through securing the collaboration of mental health workers from other disciplines. The social worker, the psychologist and the special education teacher are potential valuable allies. It is important that the pediatrician be aware of such professionals in the community and avail himself of their services. Many school systems em- 
ploy not only psychologists but social workers and special education teachers who can be of assistance to the physician in his over-all management of the case. Many pediatricians employ the services, part-time or full-time, of social workers and psychologists to help them in their routine practice. These professionals, if accepted as allies, will usually respond with valuable assistance. Conversely, if the pediatrician erects a sort of medical barrier against accepting the services of these individuals, conflict arises and the patient and the family suffer.

A final method of treatment available to the pediatrician is that of insight-producing psychotherapy. This is the method by which the child or his parents are given additional understanding of the inner conflicts and diffculties from which they suffer. This is the method which the pediatrician most frequently associates with psychiatry. $\mathrm{He}$ fears it as an unknown area, and often remains distrustful of it even when it is in use by the psychiatrist. Even though the average pediatrician has had little formal training in this respect, as mentioned earlier, it does not necessarily follow that he should never under any circumstances approach this area. If he becomes interested in the emotional problems of his patients he may perhaps do further reading and even seek some psychiatric supervision. Certainly it is reasonable to hope that more pediatricians will begin to allow themselves more curiosity and learning in this area. Some of the basic ingredients of such insight-producing psychotherapy are here presented in the hope that they will diminish misconceptions and encourage further learning.

\section{ESSENTIAL PREPARATIONS FOR INSIGHT-PRODUCING PSYCHOTHERAPY}

If and when a pediatrician decides that insight-producing psychotherapy is essential and that he himself will be the therapist, there are certain steps which he should take in preparation for this treatment. First of all, he must make an accurate evaluation of the patient's personality, in regard not only to current function but also to past growth. Secondly, he must formulate some treatment plan with goals which would appear attainable.

Next, both the patient and the physician must agree that emotional problems exist. To the pediatrician, such an agreement will more often than not take place between him and the parents, although at times it also may take place between him and the child. Many youngsters, especially those suffering from uncomfortable neurotic problems, are capable of agreeing that they have "worries." Others, especially those who are acting out difficulties, like their adult counterparts, tend to find the problems only in the world around them. Nevertheless, it is essential that the pediatrician come to this agreement with parents and wherever possible with the child also. Then it becomes possible to work out a plan both with the parents and the child. The parents are helped to understand that the youngster will have to be seen at regular intervals and even the youngster himself is given an understanding of this agreement. It is presumed that the healthy part of the parents and of the child will ally with the physician and participate in the treatment plan. Many parents, after initially agreeing to treatment, begin to resist as will the youngster. If, however, the family situation is sufficiently healthy, the probabilities are that both parents and child will continue to participate.

\section{COURSE OF PSYCHOTHERAPY}

Once the physician and patient have agreed upon a course of psychotherapy, the unhealthy aspects of the patient's personality begin to resist the treatment procedure. In the case of the adult patient he has agreed to come at specified times and to talk during these sessions about those things which are most troublesome to him. Such an agreement means that he will have to undergo some uncomfortable moments. It is his responsibility to arrive at appointments on time and to verbalize as freely as he can. In addition to all this he has agreed to pay for such treatment. His hope is to be rid of his uncomfortable symptoms. Soon, however, the unhealthy part of his personality begins to sab- 
otage the treatment. He may forget appointments at times, or arrives late. During his sessions he may find that he has nothing on his mind. He may discuss inconsequential matters instead of those things which are most important. These, and many other methods, are used as resistance by the patient. Most of them take place on an unconscious level. The healthy part of the patient's personality is still dedicated to participating properly in the treatment, but resistance makes such participation arduous.

The patient also distorts his relationship to the physician through transference. As mentioned earlier, he brings into the therapeutic relationship many emotions which have been felt toward early important figures in his life, particularly his parents. In the case of the child, the parents are still very real and present. In the case of an adult, they are in the past, but still the transference emotions are important. The patient may, for a time, invest the physician with positive transference, and be anxious to please and like him. At other times transference will be negative with feelings of hostility, distrust and resentment. Since such feelings are brought from outside the therapy and only invested on a neutral physician, they are unrealistic and need be understood by the patient. Transference feelings exist elsewhere in the patient's life, but are usually not dealt with and eventually understood as they are in psychotherapy.

The task of interpreting resistances and transference is a major task in the course of psychotherapy. The physician attempts to help the patient understand, for instance, that a part of him wants to be late, or wants to forget appointments. He also helps him understand that the apparent positive or negative feelings are really similar to those which he has felt toward another important figure. One of the most frequent mistakes of the nonpsychiatric physician is to counter-react to resistances and transference. He becomes irritated when the patient forgets an appointment or shows negative transference. The result is that the patient learns little, if anything, about his own neurotic problems.
As resistances and transference are interpreted, the basic unconscious conflicts emerge and the patient truly learns about many of the factors which have operated beneath his awareness. His symptoms are then better understood and diminish in intensity. Finally, the patient achieves object relationship. This term merely means that he relates to others realistically, rather than with a covering of neurotic distortion. The pateint has worked through some of his immaturities, and defenses against them, and is capable of relating to others on the basis of the situation as it exists.

\section{FINAL COMMENT}

As would appear evident from what has been said, the psychiatrist literally "is not coming"--not for many years. Until then, every physician will have to accept some responsibility for the care and treatment of the mental and emotional problems of his patients. Some physicians are, by virtue of their own personalities, interested in and adept pupils for insight producing psychotherapy. Treatment of emotional problems is a broad field, however, and there are many different ways by which a physician can improve the emotional adjustments of his patients.

The pediatrician, with his responsibility for the health of children, has many ways of contributing to our national efforts in mental health. He can stimulate the community to improve its psychiatric facilities and services. He can improve his own knowledge of mental health principles. He can utilize various methods to help the patients in his own practice. He can join his psychiatric allies in a team effort and, if he desires, accept their asisstance in the management of selected cases.

\section{REFERENCES}

1. Action for Mental Health. Joint Commission on Mental Illness and Health. New York, Basic Books, Inc., 1961.

2. Mental Illness and Mental Retardation. Message from the President of the United States. House of Representatives, 88th Congress, 1st Session, Document No. 58, Feb. 5, 1963.

3. A National Plan to Combat Mental Retardation: Report of the President's Panel on Mental Retardation, U. S. Government Printing Office, Washington, D. C., 1963. 